\title{
Maimonides and a Legal Response to Artificial Intelligence*
}

\author{
MOA DE LUCIA DAHLBECK \\ University of Gothenburg
}

\begin{abstract}
In the $13^{\text {th }}$ century, Maimonides revolutionized Jewish jurisprudence by arguing that in contrast with traditional rabbinic views of the Torah's commandments (i.e. the written divine law) as ends in themselves, Scripture's commands were better viewed as means to the end of a truthful, rational understanding of the world. The material content of the law was always to be understood as accompanied by an additional layer of fundamental formulations of beliefs and opinions regarding God and nature. Maimonides' theory of law began with the idea that human nature was perfected to the extent that it achieved a rational understanding of things. By holding that the ultimate end of law was to function as a means for the realization of human perfection, Maimonides placed a tool for social stability at the heart of the individual striving for ethical flourishing. In this article, I argue that Maimonides' understanding of law's ultimate end may help us deal with the question of how to approach the phenomenon of an ever-increasing reliance on AI in modern life from the perspective of law. My argument suggests that AI can be understood as a threat to law's natural and (according to Maimonides) necessary participation in the ethical process towards intellectual perfection.
\end{abstract}

Keywords: Maimonides, artificial intelligence, Jewish jurisprudence, legal theory, law's ultimate end, ethical flourishing.

* This work was supported by Riksbankens Jubileumsfond (P17-0719: 1). For invaluable comments on earlier drafts of this paper, I am grateful to Valentin Jeutner, Gregor Noll and Johan Dahlbeck. Two anonymous reviewers provided thoughtful and detailed comments that greatly improved the final version of this article. 


\section{ARTIFICIAL INTELLIGENCE AND THE QUESTION OF LAW'S END ULTIMATE}

This article aims to show that, surprising as it may seem, a medieval conception of law's ultimate end developed in a religious context can help us grasp the challenges posed by the phenomenon of artificial intelligence (AI) to contemporary legal practices. The article will also suggest that flipping the focal points of the usual questions asked when reflecting upon AI's effects on law - from AI to law itself - may serve us in developing a considered legal response to a reality in which legal practices may involve agents and actors lacking human attributes.

Instead of focusing on the problems of application caused by (mostly self-learning and autonomous) AI when trying to come to terms with the use of AI within legal practices, I suggest placing the focus on law's ultimate end. Doing so while starting out from the instances in which AI seems to enhance rather than challenge the human ability to comply with laws, will enable an analysis of the impacts of AI on law that is not tied to a specific legal context or practical problem. We could imagine, for example, using AI to guarantee compliance with drunk driving laws. Cars could be equipped with an AI that takes over the function of driving manually whenever its sensory devices perceive an abnormal pattern of movement. Analyzing the legal effects of AI while keeping in mind instances such as this will help us outline a response to AI that is general enough to function as a starting point for any kind of specific discussion of encounters between AI and law.

The theoretical basis for this response is the medieval Jewish scholar Maimonides' (1135-1204) account of the ultimate end of law. Although it may appear far-fetched to turn to a medieval thinker to confront problems facing contemporary legal/technological discourses, the reasons are more straightforward than they may first seem. Because the aim of this paper is to find an appropriate legal response to AI through an outline that focuses on law's nature rather than that of AI, it will use arguments that concern the metaphysical relationship between human nature and law. Jewish jurisprudence, in general, is a valuable source for this kind of endeavor as it treats normative issues as parts of a greater ethical and metaphysical scheme (see Elon, 1985:221). Maimonides' philosophy makes for a specially interesting focal point within this tradition as he explicitly infers his jurisprudential suggestion that law is a means towards a higher (beyond social) end from investigations into human nature (see Elon, 1985: 222-4; Dorff, 1978). I argue that some of Maimonides' metaphysical reflections on law may serve us in making a careful consideration of whether the legal discourse ought to be generally enthusiastic or skeptical towards an 
increased use of AI-technology in human practices regulated by law. To be clear, my use of Maimonides' philosophy is to be regarded, not as an attempt to comprehensively account for his legal and metaphysical theories, but rather as a source of inspiration for an independent reflection upon law and its ultimate end.

In what follows, I will first extract two answers to the question of law's ultimate end from Maimonides' scholarly exchange with contemporary Jewish jurisprudence on the relationship between human nature and law. I will argue that a close reading of the two different positions deduced from these Rabbinic discussions reveals that Maimonides' immaterial concept of law's ultimate end (as a means to arriving at an end that is nonmeasurable in an empirical sense) gives a robust metaphysical account of the nature of law as well as the human being. Next, I will discuss how this account opens up for a critical understanding of the kinds of human interactions with AI that have generally been considered beneficial (or at least harmless) from the perspective of legal practice. Having laid out the potentially problematic aspects of apparently unproblematic human interactions with AI, I will argue that this enables a considered evaluation of whether legal discourse should side with those who are generally skeptical or enthusiastic towards the use of AI. Lastly, I will conclude by arguing that Maimonides' conception of law - as the bearer of an instrumental, as opposed to intrinsic, value - settles the question of legal response to $\mathrm{AI}$ in favor of the skeptical side. This leaves us with a warning against an unqualified embracement of the incorporation of AI techniques in legal practices.

Usually when contemplating AI, legal discussions tend to focus on cases involving a) AI that is complex enough to replace parts of, or the entire, human cognitive process and $\mathrm{b}$ ) legal rules that depend on the evaluation of some form of subjective or mental criteria that originate from said process (intent, negligence, diligence, common sense etc.). This focus seems natural considering how the problems that these cases highlight often concern the application of norms involved in the administration of justice. In other words, they are problems that affect norms indispensable for a well-functioning civil, penal and humanitarian law. However, there are two factors that motivate a different focus when considering the impacts of AI on law. The first factor is the multifaceted nature of AI. The second is the inconclusive result that a principal focus on the legal problems caused by (mostly) complex AI may lead to. I will discuss each of these factors in turn.

Because of the lack of a universally accepted, informative definition of AI, it may seem difficult to argue for a legal response towards AI that does 
not depart from particularities, such as the kind of legal norms affected or the form of AI involved. However, to do so conceals the fact that there may be problematic issues related to the incorporation of AI into law-regulated human activities that are neither immediately visible nor concerned with the application of law. Specifying the two factors mentioned above as motivations for an alternative focus when contemplating AI's impacts on law, will hopefully serve to clarify this further.

With respect to the first factor, it should be noted that technological development has generated a widening of the significance of the concept of AI. Today, AI interventions in human activities range from cases where the interaction between machines and humans is minimal (e.g. pattern analysis in big data) to those in which the $\mathrm{AI}$ is fully interactive (robotics and chatbots); from interventions that require no learning process at all (only the programming of inputs - outputs) to those that are entirely dependent on machinic self-learning; from interventions the decisions of which are taken by human authors, to those in which AI is acting autonomously. Naturally, cognitively sophisticated kinds of AI - the kind that can be understood 'as a growing resource of interactive, autonomous, self-learning agency, which enables computational artifacts to perform tasks that otherwise would require human intelligence to be executed successfully' - will cause more obvious problems for legal practices than the kind that amounts to technical improvements of human activities (Taddeo and Floridi, 2018: 751-752). It is not strange, then, that the discussion of AI from the perspective of law has been informed by a general fear of the ways in which AI may undermine a meaningful human control over events, such as the application of a given legal rule. However, the cases of human interactions with AI in which the effects of AI on legal practices are obviously problematic are not the only ones conceivable.

As for the second factor, so called "nudging" is one example of a state practice involving a mix of different kinds of AI which very rarely is met with resistance from legal scholars. ${ }^{1}$ Nudges are by definition nonregulatory measures that aim to influence individuals to change behavior without removing their freedom of choice (Ranchordás, 2019). Strictly speaking, this means that nudges cannot be regarded as challenging to the concept of human agency in ways that could affect the application of laws. To this end, they constitute good examples of a public and normative use of AI that appears completely harmless for legal practices and therefore natural to endorse from a perspective of law. There are also examples of

\footnotetext{
Nudging denominates incentives given by smart cities for people to act in certain determined way which they have established by way of employing the Internet of Things, big data, and algorithms (see Ranchordás, 2019).
} 
legal contexts in which one and the same kind of AI-technology provokes both critical and endorsing stances (see, e.g., Cath, 2018; Floridi, 2018; Nemitz, 2018; Armstrong and Ray, 2019; Braun, 2019). This is visible within the discourse on international humanitarian law (IHL) and its attempt to determine the legal status of lethal autonomous weapons systems (LAWS). The legal debate on LAWS contains voices that express enthusiasm for AI (of a highly sophisticated, self-learning and autonomous kind) in so far as it may safeguard fundamental humanitarian principles and values (such as the principles of discrimination, proportionality and the prohibition of unnecessary suffering). The same debate also contains voices, however, that express skepticism towards the same kind of AI due to its alleged threat to the very same principles and values (ibid.). Since both stances are considered to be equally substantiated and well-argued, the result is a stand-still in the negotiations on a new legal regime dealing with LAWS (Sturken et. al, 2004; De Lucia Dahlbeck, 2020).

In sum, scholars have tended to adopt one of two stances within the legal discourse: a skeptical stance and an enthusiastic stance. The skeptical stance can mostly be seen in reflections on legal norms that incorporate a subjective mental criterion, the interference of which makes AI seem to undermine a legal requisite of necessary human control (Ormond, 2020: 5). The enthusiastic stance emerges rather from contemplations on the impacts of AI on laws that aim at establishing a specific conduct without an additional requirement of intent, will or neglect. ${ }^{2}$ This stance is thus often a response to less sophisticated, more mechanical forms of AI that create low-level interferences with technical and non-cognitive norms, such as speeding or administrative matters (see Taddeo and Floridi, 2018: 752). The co-existence of both of these stances within legal discourse goes to show why it may be relevant for legal theory to seek an approach towards AI that does not depart from the questions of what AI is and does to law. To this end, it could be interesting to try out as new starting points the questions of what law is and what it needs from AI.

\section{MAIMONIDES AND LAW'S ULTIMATE END}

The Jewish tradition of thought has always treated normative matters as part of religious and thus metaphysical problems (Elon, 1985: 221). Arguably, this can at least partly be explained by the fact that the broadest definition of Jewish law-Halakha - encompasses legal as well as religious/

\footnotetext{
A rule prohibiting driving a car after consuming (a certain amount of) alcohol is an example of what I refer to as the second kind of legal rule and a rule prohibiting the willful killing of another human being is an example of the first.
} 
ethical matters. Halakha refers to both written versions of the Mishnah (the oral complement to revealed law: Torah), as well as to doctrine and jurisprudence (Gemara) on how to interpret, analyze, and explain the meaning of Mishnah in specific contexts (see, e.g., Butterworth, 2007: 219250). Thus, the main source of Jewish law (the Halakha) teaches not only civil matters, but also issues concerning beliefs, rituals and ethics. ${ }^{3}$ Menachem Elon (1985: 222) elaborates on the special character of Jewish theory by explaining that "critical analysis, legal terminology, methods of interpretation, and all the other methods of explication and legal creativity are common to all branches of halakhah". Supporting the idea that Maimonides was situated within a tradition of thought that both substantially and methodologically links legal (social and moral) matters with religious (metaphysical and ethical) convictions, he adds that

anyone who has participated in a Talmudic discussion will realize that there is no difference between a discussion of civil law and a discussion of the law of sacrificial offerings or ritual impurity, as regards the use of legal concepts and terminology or in the way the laws are discussed. (ibid.)

It is evident from Elon's comments that medieval Jewish law distinguished law from faith in a very particular and, from a western secular perspective, highly unconventional manner. Because, as Charles Butterworth (2007: 219) clarifies,

[p]roperly speaking, there is no philosophy of law in medieval Judaism and Islam. In its place is jurisprudence, that is, the art or science that seeks to explain what the revealed law of either tradition means with respect to one particular situation or another and how it is to be applied.

This jurisprudence (Gemara) amounted to a theoretical explanation of how to move from "what is explicitly spoken of by the particular revealed law to what is not - extending that law to new phenomena or new applications" (ibid.). In other words, law in medieval Judaism is "divine law handed down to a particular religious community by a divinely inspired law-giver, a prophet or a messenger of the Almighty" (ibid.). Understood in this way, law amounts to a description of the righteous way of living for a person faithfully committed to his or her religious community, whereas its surrounding jurisprudence will amount to theology, although a highly technical and philosophically oriented theology (see Butterworth, 2007:

\footnotetext{
The most important source of Halakhah (the law) is the Talmud which contains the Mishnah: the first written down record of the oral law, and the Gemara: the record of the Rabbinic discussions following this writing down (see Elon, 1985: 222).
} 
220). For Butterworth (2007: 221), even though it was generally recognized that there existed an alternative conception of law (one that saw law as a man-made vehicle for social stability), philosophers belonging to the medieval tradition considered only divine law worthy of investigation and commentary.

Maimonides, however, recognized another way of relating to the alternative conception of law as a political and man-made vehicle for ensuring social stability:

The governance of the city is a science which provides its inhabitants with the knowledge of true happiness along with the way of striving to attain it; the knowledge of true misery along with the way of striving to keep it away; and the way of training their moral habits to reject the presumed kinds of happiness so that they do not take delight in them or covet them. It explains the presumed kinds of misery to them so that they do not suffer from them or dread them. Similarly, it prescribes laws of justice for them by which they can order their communities. The learned men of past communities, each according to his perfection, used to fashion regimes and rules by which their kings would govern the subjects. They called them nomoi, and the nations used to be governed by those nomoi. (Treatise on the Art of Logic XIV quoted in Butterworth, 2007: 222).

It is clear from this passage that Maimonides, in contrast to his historical predecessors, considered social law (nomoi) worthy of study as it clearly made for an integral part of how to live according to divine law (halakha). The governance of the city (i.e., law as a vehicle for social stability) "provides its habitants with the knowledge of true happiness along with the way of striving to attain it" (ibid, emphasis added). The question of faith does not seem to have been quite as naturally separated from political laws for Maimonides as it was for some of his contemporaries. This can also be deduced from how he described, in the quoted passage, man-made (political) laws as integrated means towards the fulfillment of the divine law's stipulation of true happiness. We can take this as an indication of the fact that Maimonides' understanding of the ultimate end of law emerges from his conception of the relationship between faith and legal compliance.

According to Moshe Halbertal (2016: 137), Maimonides demonstrated in the Commentary on the Mishnah that he broke with the Rabbinic tradition by not regarding "faith simply as confidence in God and dedication to Him and his word". Arguing that compliance with a given set of (divine) rules was not enough to demonstrate faith, Maimonides required that such compliance had to be complemented by a condition of 
a wholehearted contemplation of a set of propositions and cognitive principles. According to Maimonides, these propositions and principles functioned not only as evidence of a persons' faith, but also as a precondition for being a member of the Jewish society; that is, as a precondition for membership in a particular - and by political laws (nomoi) - delimited social entity (ibid.).

Arguably, what made Maimonides take a position that dissociated him from the traditional Rabbinic understanding of how to demonstrate faith (as well as membership in the Jewish polity), was his involvement in "the cultural realm of Aristotle and his interpreters" (ibid.). Maimonides' rejection of the traditional rabbinic understanding of how to evaluate someone's membership to the Jewish community was thus a natural continuation of having altered the philosophical starting point for elaborations on the essence of human nature. Grounding his concept of faith (in both a social group and a given set of religious beliefs) in Aristoteles' philosophy of human nature had a direct effect on Maimonides' legal theory. It made him reject the Talmudic view that religious as well as cultural loyalty to the Jewish community was demonstrated through a considered compliance with norms and that no further intellectual predisposition was needed (see Halbertal, 2016: 136-137). In the Essay to Resurrection Maimonides (1985: 212-3) established that he "therefore published principles that need to be acknowledged in the introduction to the Commentary on the Mishnah regarding prophecy and the roots of tradition and what every Rabbinite had to believe concerning the Oral Law".

When contrasting Maimonides' position with that of his contemporary interlocutors, it is evident that Maimonides rejected their strict focus on the application of norms for determining someone's participation in legal and moral (religious) communities. Maimonides rejected this as the decisive criteria of membership in favor of one that added to it a certain empirically non-demonstratable - intellectual predisposition (see Halbertal, 2016: 136-137). As mentioned, the immaterial aspect of Maimonides' proof of faith most likely originated in his "deep internalization of Aristotelian thought regarding the nature of the good life". This, in turn, brought "about a greater emphasis on beliefs as a central component of Jewish identity" (ibid., 138, emphasis added).

Accordingly, it can be read in the Introduction to Maimonides' Commentary on the Mishnah that man's "purpose is but one activity, and all the other activities are to maintain his existence so he can perfect that one activity, which is to apprehend the intelligibles and know the truths as they are" (1964: emphasis added). Further on in the same work (1964: 241), the same essential message is conveyed: 
It is proper for a person to deploy all the powers of his soul to advance knowledge ... and to set before his eyes a single purpose, that is, apprehension of God, may He be glorified and exalted, in accord with a person's ability, that is, his knowledge. And he should apply all his actions, his movements and speech toward that purpose.

Drawing on this account, law - as the organizer of human activities par excellence - is always subordinated to the ethical goal of becoming more rational. To this end, law must be seen as having one direct purpose, to deal with bodily needs, and one indirect yet much more fundamental purpose, to make human beings become rational (i.e., to understand things according to their true causes).

On my reading of Halbertal's account of Maimonides' understanding of the ultimate end of law, legal theory must relate and function with respect to a three-level structure: the establishment of (a) sociopolitical stability aimed at facilitating (b) the development of moral qualities, which are necessary for (c) the achievement of the highest human nature. The law and its concrete norms (level (a)) constitutes a direct means for (b) the achievement of the development of moral qualities and are, as such, also indirect means for the achievement of (c) the ultimate end of a life of inquiry and contemplation. The creation of a stable society depends on the upholding of laws, which are both conditioned by and means for a successful inculcation of certain moral qualities among the subjects of a society thus formed. In short, the scheme can be summarized as follows. Norms, the application of which can be empirically measured, are means for inculcating behavior in accordance with certain given moral qualities in human beings. These moral qualities are, in turn, necessary both for continued respect of the norms as well as for the striving towards the end of rational understanding. Behaving in accordance with norms that reflect given moral qualities will make human beings appreciate these qualities. Once they appreciate them, humans will develop them further so as to use them to establish the bodily security necessary for turning society into a means for the individual's striving towards intellectual inquiry and contemplation.

Halbertal (2016: 139) writes that Maimonides by affirming the Aristotelian explanation of the human essence as a constant striving for virtues (knowledge being the highest of these), placed his metaphysical conviction "at the heart of Judaism" and that this, of course, "had a farreaching effect on the status of Halakhah". This formulation seems to confirm my reading that Maimonides constructed a pragmatic link between law and religion as reciprocal tools for establishing obedience and social order in order to achieve a further end beyond the social. 
Because Halakha contains both ceremonial (religious) and civil (social) prescriptions and prohibitions, Maimonides appears to have been writing about law in general when he suggested that we should regard it as a means to the highest human end of becoming a knowing creature.

From this brief review, it is possible to extract two different approaches to the question of law's ultimate end. On the one hand, we have seen the view represented by Maimonides' rabbinic interlocutors who regarded a correct application of the law's norms as sufficient proof of faith. According to Halbertal (2016: 139), they portrayed "man, alone among the creatures, [as] granted free will" and what characterized him as "the ability to use his will to subject his desires and lusts to laws and models of proper conduct". For a legal philosopher adhering to this view, "[i]t is [law] halakhah that directs man in doing so, and fulfillment of [law] halakhah in all its particulars is the essence of human distinctiveness" (ibid., emphasis added).

On the other hand, we have the Maimonidean conception of law's ultimate end as being entirely conditioned by Aristoteles' concept of human perfection as a striving towards a perfected intellect. A legal philosopher adhering to this view today is thus conditioned to consider law as a means for the fulfillment of an ultimate end beyond law. According to the understanding of law that Maimonides entertained, law is a necessary means for organizing human inter-activity meant to establish and uphold the moral order needed for human beings to individually approach the highest end of a true understanding of things. According to his perspective, then, a description of law's end as a striving for its own compliance is not necessarily erroneous, but it is insufficient. It is insufficient insofar as it fails to account for the ultimate purpose towards which any enforcement of any given law ought to be directed. A satisfactory general compliance with law can never be seen as more than preliminary evidence of the achievement of this higher end beyond the social. Halbertal (2016: 139) elaborates:

He [Maimonides] therefore made fulfillment of the active commandments into a means rather than an end and supplemented the halakhah with what he took to be an additional, very important layer of effort: the binding formulation of proper and true beliefs and opinions regarding God and the world.

According to Halbertal, law does not hold an intrinsic value for Maimonides. The compliance with law does not suffice to prove a human being's virtue or perfected nature. Rather, this can only be measured by how well a given law functions as an instrument for instigating the intellectual process necessary for the individual formulation of such opinions and beliefs that 
correspond to a true representation of things. To judge by Halbertal's interpretation of Maimonides' view on halakha, real faith (and, in extension, loyalty to a political body) can never be proved merely by a specific conduct. This is because proof of faith (and loyalty to a political body) is constituted by an intellectual, internal predisposition which lacks empirically measurable features. Conversely, the external features of the requirements of loyalty and faith do not in themselves suffice to prove the attainment of the end behind the requirements of faith or loyalty, because that purpose is empirically non-provable in its nature. To this end, conduct can only ever function as one - and never the sole - indicator of the existence of faith (or loyalty to a society held together by given laws).

Maimonides' affirmation of an Aristotelian concept of virtue, as a mental rather than a physical and thus empirically measurable quality, affected many aspects of his legal theory. For instance, it made him question the traditional conception of the immortality of the soul as a physical reward of sorts for hardship and dutiful compliance with the Scripture's norms during a lifetime. His altered understanding of human nature pushed him instead into perceiving immortality of the soul as the immediate - and immaterial - sensation related to understanding the nature of things (see Halbertal, 2016: 140). It follows from this that leading a life aimed at fulfilling the purpose of divine law meant something much more to Maimonides than merely occupying oneself with certain actions because they are thought to have an instrumental value in relation to one's position in the afterlife. For Maimonides, the act of complying with a (religiously or politically) ordained norm aimed at securing the fulfillment of the divine law played a direct part in providing the reward of fulfilling this law itself. This is so insofar as all laws are but means to disseminate and install, not a certain conduct, but the values necessary for beginning to approach the intellectual capacity required for experiencing true happiness (i.e., virtue); that is, the experience of knowing happiness according to the divine law.

On the same note, Albert Friedberg (2003: 248) writes that:

Maimonides explains that the acquisition of metaphysical knowledge is often called "life". He further demonstrates exegetically that this acquisition of metaphysical knowledge is "good"; and "good" is synonymous with the world-to-come - a world that is entirely "good". (Quoting Halkin and Hartman, 1993: 249).

Concurring with this reading, Halbertal (2016: 143) points out that in both the Commentary on the Mishnah as in the later Mishnah Torah, Maimonides argued that Scripture's references to physical rewards and punishments for observance of, or non-compliance with, its commandments should be 
understood as unrelated to the final purposes of these commands. These rewards and punishments should rather be understood metaphorically in relation to the substantial message of Scripture, whereas their literal meaning was to be read as applicable in relation to its organizational function; as a means for facilitating "man's pursuit of his true purpose knowledge of the Creator" (ibid., emphasis added). Clearly Maimonides understood the Bible's social commandments - the law - as a tool corresponding to a goal much more fundamental than the mere establishment of the conduct prescribed by that law. In the Mishnah Torah $(1974,9: 1)$ he wrote that God,

has further promised us in the Torah, that, if we observe its behest joyously and cheerfully, and continually meditate on its wisdom, $\mathrm{He}$ will remove from us the obstacles that hinder us in its observance, such as sickness, war, famine, and other calamities; and will bestow upon us all the material benefits which will strengthen our ability to fulfill the law, such as plenty, peace, abundance of silver and gold. Thus we will not be engaged all our days, in providing for our bodily needs, but will have leisure to study wisdom and fulfill the commandments, and thus attain life in the world to come.

To judge by this passage, what may be perceived as the immediate and physical reward for a successful observation of Scripture's commands is, for Maimonides, nothing but the achievement of a particular state of being for those who find themselves bound by the commands. This would be a state of being in which the continued observation of the commands follows naturally for those observing them. The act of starting to observe the commands would liberate the intellectual energy and capacity needed to contemplate them further, and to attain a deeper understanding and affirmation of them. From this it is possible to conclude that, for Maimonides, leading a law-abiding life amounted to much more than merely acting in line with certain norms of conduct with the hopes of a future physical reward. According to Maimonides, the physical pleasures promised in the Bible for leading a virtuous and law-abiding life should rather be understood as preliminary and immediate rewards aimed at helping people reach the more fundamental goal of obtaining a deeper understanding of things.

\section{TWO LEGAL APPROACHES TO AI}

From Halbertal's examination of Maimonides' attempt to unify, compile and clarify halakha, I wish to take with me the description of two opposing ways of portraying the ultimate end of law. The first considers law's 
ultimate purpose as achieved when its rules are complied with completely. This view emanates from an idea of human essence as distinguished by the existence and use of free will. It is by subjecting human desires and physical instincts to the control of the will - by for instance choosing to follow laws and rules that dictate a given conduct - that a human being can perfect her essence and achieve true virtue. According to this position, a perfect compliance with law can be regarded as proof of a society inhabited by law-abiding (perfect) individuals. This, in turn, indicates that human beings have found in law the only necessary means for attaining their true natures and highest level of virtue.

If we look at the possibility enabled by AI-technology for human beings to sometimes achieve perfect compliance with law (from the perspective of this conception of law's ultimate end) an enthusiastic stance towards AI seems appropriate. Going back to the initial example of AI taking over the human capacity to drive whenever it perceives drunk driving, it seems reasonable to hold that such a takeover will be applauded from the perspective of a legal theory that equals perfect compliance with law's ultimate end. From this perspective, the use of AI-technology demonstrates the fulfillment of human nature insofar as this nature amounts to the will to secure a perfect compliance with laws aiming at avoiding accidents and traffic infractions and at causing social stability.

Arguably, it could be objected that AI takes over, more than helps, humans in the task of willing the right thing according to this conception of law's ultimate purpose. This objection would be motivated if such a takeover would suspend the full realization of human nature, since that realization is conditioned by the deliberate use of the will to combat animalistic desires and instinctive and automatic behavior. However, this objection can be dealt with by reference to the fact that the use of the will seems not to be permanently trumped by AI. In fact, it is merely displaced from the actual moment of conduct to the moment of creation of machines and tools to be used in that conduct.

The other way to conceive of law's ultimate end which is discernable from the Maimonides-Rabbi discussion amounts to regarding the goal of a high degree of compliance (with divine as well as man-made laws) as preliminary in relation to the ultimate goal of making people think rationally. We may recall that according to this view, human essence consists in a constant striving towards understanding; a striving that manifests itself through an increase in the ability to determine the quality of ideas and distinguish between true and false accounts of the world. Although this view can easily be combined with an idea about the specific content of the understanding towards which human nature naturally 
strives (which it indeed was in Maimonides' case), the perspective's focus is clearly not on a given physical result (as manifested by a stable society for instance) but on the process of complying with law and what this process would do to the human intellect.

If this view of law's ultimate end is respected when considering the possibility that AI may establish perfect compliance with law, the stance that follows will naturally be more skeptical. Its skeptical response to AI stems from the fact that this view emerges from a metaphysical conception of human nature as something essentially procedural, which cannot be empirically proven by a given state of affairs or behavior. This is to say that the metaphysical explanation of human nature, upon which this view hinges, contains a flexibility that must be respected even when dealing with derived concepts, such as the human highest good and the ultimate end of law. In accordance with the metaphysical idea of human nature that Maimonides relies upon in his discussion of halakhah, human virtue can never be attached to an empirically measurable variable such as compliance. Instead, becoming virtuous - as in perfecting one's nature amounts to approaching a rational understanding, rather than becoming a being whose behavior corresponds to having acquired said understanding. This conception of the purpose of all human activities must alter the legal response towards AI. Its focus on process requires us to be more critical towards the fact that AI may render superfluous the active human participation in achieving law's preliminary goal of establishing a society populated by a certain kind of individual.

In removing the need for humans to participate in the process of establishing a society populated by individuals acting according to a given ideal, human beings are further removed from realizing the ultimate end of law which is to help perfect their own essences. They may indeed be brought closer to accomplishing law's preliminary goal of social stability, but this goal is only valuable insofar as it actually constitutes a means towards the ultimate goal of making human beings more rational. According to the conception of the ultimate end of law that Maimonides defends, the result of introducing AI into legal practices is - even in those more obvious instances where AI complicates the application of a law - a paradox. In rendering the human ability to comply with laws less human, human beings remove themselves from the ultimate goal for which all law should be created.

To make this last point clearer still, let us go back once more to our example of cars taking over the capacity to drive from humans whenever these seem to have been drinking. People driving cars without an AItechnology in place are forced to reflect upon issues that are related to the 
deeper social and moral reasons behind the law, to the extent that these issues are intrinsically connected to the considerations one is forced to make when contemplating using the car despite a norm prohibiting this. These issues vary from the socio-economical costs of having to face the legal consequences of breaking a law, to the emotional and moral cost of potentially having caused physical harm to other people if driving indeed leads to an accident. The reflections prompted by not having a technical device guarantying one's compliance with the law are perhaps not completely denied to people by the introduction of AI, but they are rendered unnecessary. And this is, for Maimonides, sufficient to make AI an obstacle for the achievement of law's ultimate purpose.

All in all, it would seem that we arrive at the following conclusion with respect to the question of AI's impact on law from the perspective of Maimonides' conception of the ultimate end of law. An uncritical endorsement of AI, even in those instances where AI does not jeopardize, but rather enhances, the human ability to comply with the law, risks making us blind to the fact that AI always obstructs the fulfillment of law's ultimate end. To this end, an uncritical legal endorsement of AI in cases when AI merely enhances human compliance with law does not consider Maimonides' notion of why we have laws geared at social stability in the first place. For him, we have laws geared at social stability to assist people in fulfilling their own existential purpose of becoming more rational. This is the most important conclusion that I would like to stress in relation to the encounter between Maimonides' idea of the ultimate end of law and an increased reliance on AI in different kinds of legal practices. In light of all of the above, my final reflection is therefore that Maimonides provides us with good arguments for considering all forms of AI - even simple AI that is inoffensive to human agency - as detrimental to the fulfillment of law's ultimate end insofar as that end is construed as a striving towards intellectual reflection, and not as a mere adaptation of behavioral patterns to a given ideal.

\section{BIBLIOGRAPHY}

Armstrong, H. and Ray., 2019: “A Working Model for Anticipatory Regulation”, Nesta (ed.) URL =<https://nesta.org.uk/report/a-working-model-for-anticipatory-regulation-aworking-paper/>.

Braun, R., 2019: “Artificial Intelligence: Socio-Political Challenges of Delegating Human Decision-Making to Machines”, IHS Working Paper Series 6: 24.

Butterworth, C., 2007: "Philosophy of Law in Medieval Judaism and Islam”, in A Treatise of Legal Philosophy and General Jurisprudence vol 6, A History of the Philosophy of 
Law from the Ancient Greeks to the Scholastics, ed. F. J. Miller and C-A. Biondi, 219250, Dordrecht: Springer.

Cath, C., 2018: "Governing Artificial Intelligence: Ethical, Legal and Technical Opportunities and Challenges”, Philosophical Transactions of the Royal Society A Math Phys Eng Scie. 376, 20180080.

De Lucia Dahlbeck, M., 2020: “AI and Spinoza: a Review of Law's Conceptual Treatment of Lethal Autonomous Weapons Systems", AI \& Society, DOI: https://doi.org/10.1007/s00146-020-01014-x.

Dorff, E., 1978: "Judaism as a Religious Legal System", 29 Hastings L.J. 1331, URL $=<$ https://repository.uchastings.edu/hastings_law_journal/vol29/iss6/4>.

Elon, M., 1985: “The Legal System of Jewish Law”, New York Journal of International Law and Politics 17: 221-244.

Floridi, L., 2018: "Soft Ethics, the Governance of the Digital and the General Data Protection Regulation”, Philosophical Transactions of the Royal Society A Math Phys Eng Scie. 376.

Friedberg, A. D., 2003: "Maimonides' Reinterpretation of the Thirteenth Article of Faith: Another Look at the 'Essay on Resurrection',", Jewish Studies Quarterly 10: 244-257.

Halbertal, M., 2016: Maimonides: Life and Thought. New Jersey: Princeton University Press.

Maimonides, M., 1974: "Laws Concerning Repentance" in The Book of Knowledge (Mishneh Torah), transl, M. Hyamson, Jerusalem and New York: Boys Town Press.

-1964: “Maimonides' Commentary on the Mishnah", transl. Y. Kapach, Jerusalem: Mosad ha-Rav Kook.

-1985; "Essay on Resurrection", in Epistles of Maimonides, Crisis and Leadership, ed., transl. A. Halkin and D. Hartman, 211-245, Philadelphia: Jewish Publication Society.

Nemitz, P., 2018: "Constitutional Democracy and Technology in the Age of Artificial Intelligence”, Philosophical Transactions of the Royal Society A Math Phys Eng Scie. 376, 20180089.

Ormond, E., 2020: "The Ghost in the Machine: The Ethical Risks of AI", The Thinker 83: 4-11.

Ranchordás,S.,2019:"Nudgingcitizensthroughtechnologyinsmartcities”,International Review of Law, Computers \& Technology, DOI: 10.1080/13600869.2019.1590928. Sturken, M., Thomas, D., and Ball-Rokeach, S. J., eds., 2004: The Hopes and Fears that Shape New Technologies, Philadelphia: Temple University Press. Taddeo, M., Floridi, L., 2018: 'How AI can be a force for good', Science 2018, 361: 751-752. 